\title{
Medical students' clinical performance of dealing with patients in the context of domestic violence
}

\author{
Hyun-Hee Kong ${ }^{1}$, Sunju $\mathrm{Im}^{2}$, Ji-Hyun Seo ${ }^{3,4}$, Do-Kyong Kim ${ }^{5}$ and HyeRin Roh ${ }^{6}$ \\ ${ }^{1}$ Department of Parasitology, Dong-A University College of Medicine, ${ }^{2}$ Department of Medical Education, Pusan \\ National University School of Medicine, Busan, Departments of ${ }^{3}$ Pediatrics and ${ }^{4}$ Medical Education, Gyeongsang \\ National University School of Medicine, Gyeongsang National Institute of Health Sciences, Jinju, ${ }^{5}$ Department \\ of Medical Humanities, Dong-A University College of Medicine, and ${ }^{6}$ Department of Medical Education and the \\ Institute for Medical Humanities, Inje University College of Medicine, Busan, Korea
}

Purpose: The aim of this study was to inquire about the clinical performance and determine the performance pattern of medical students in standardized patient (SP) based examinations of domestic violence (DV).

Methods: The clinical performance sores in DV station with SP of third-year ( $n=111$, in 2014) and 4th-year ( $n=143$, in 2016) medical students of five universities in the Busan-Gyeongnam Clinical Skills Examination Consortium were subjected in this study. The scenarios and checklists of DV cases were developed by the case development committee of the consortium. The students' performance was compared with other stations encountered in SP. The items of the checklists were categorized to determine the performance pattern of students investigating DV into six domains: disclosure strategy (D), DV related history taking $(H)$, checking the perpetrator's psychosocial state $(P)$, checking the victim's condition $(V)$, negotiating and persuading the interviewee (N), and providing information about DV (I).

Results: Medical students showed poorer performance in DV stations than in the other stations with SP in the same examination. Most students did confirm the perpetrator and commented on confidentiality but ignored the perpetrator's state and patient's physical and psychological condition. The students performed well in the domains of $D, H$, and I but performed poorly in domains $P$, V, and $\mathrm{N}$.

Conclusion: Medical students showed poor clinical performance in the DV station. They performed an 'event oriented interview' rather than 'patient centered' communication. An integrated educational program of DV should be set to improve students' clinical performance.

Key Words: Domestic violence, Child abuse, Elderly abuse, Undergraduate medical education, Clinical performance

\section{Introduction}

Domestic or family violence (DV) is a pattern of aggressive and intimidating behaviors, including physical, sexual, psychological, and financial attacks that occur in a domestic setting [1,2]. It encompasses intimate partner violence, child or elder abuse, or abuse by any member of a household [3]. In recent years, DV cases have been reported frequently, and social interest is increasing worldwide [4-6]. The prevalence of intimate partner violence against women was varied from $15 \%$ to $71 \%$
Received: November 8, 2017 • Revised: November 8, 2017 • Accepted: December 5, 2017 Corresponding Author: HyeRin Roh (https://orcid.org/0000-0002-3879-709X) Department of Medical Education and the Institute for Medical Humanities, Inje University College of Medicine, 75 Bokji-ro, Busanjin-gu, Busan 47392, Korea

Tel: +82.51.890.8811 Fax: +82.51.893.9600 email: hyerinr@gmail.com
Korean J Med Educ 2018 Mar; 30(1): 31-40.

https://doi.org/10.3946/kjme.2018.79

eISSN: 2005-7288

(C) The Korean Society of Medical Education. All rights reserved. This is an open-access article distributed under the terms of the Creative Commons Attribution Non-Commercial License (http:// creativecommons.org/licenses/by-nc/3.0/), which permits unrestricted non-commercial use, distribution, and reproduction in any medium, provided the original work is properly cited. 
depending on the country. It was the highest in rural area undeveloped countries such as Ethiopia [4]. The pooled prevalence rate for overall elder abuse was $15.7 \%$ with $11.6 \%$ (range, $8.1 \%$ to $16.3 \%$ ) for psychological abuse [5].

Physicians need to deal with patients of DV in the clinic very carefully [7]. Physicians frequently encounter DV in various medical clinics, including family medicine, the emergency department pediatrics, obstetrics and gynecology, surgery, etc. [7]. Thus, dealing with DV is a part of competency for medical school graduates [8]. Training about DV needs to happen at university level [9]. Domestic violence is one of core learning outcomes [10] and is one of the key items of the National Medical Licensing Exam in Korea [11].

It is quite a difficult and complex task to help patients who are suspected of being victims of DV as it is usually combined with emotional, legal, and ethical problems along with a physical illness or injury. Physicians should know and follow ethico-legal standards about DV. Furthermore, to solve DV problems, communication skills, including rapport building to let patient disclose and negotiate about treatment, is necessary. Physicians should consider the psychosocial status and perspectives of the patients and perpetrators to build rapport as patients may not recognize DV is a serious social issue or may not want to disclose DV to doctors due to psychological, social, and health system factors [12].

Previous studies on DV education for medical students focused on DV education programs, including the curriculum $[8,13,14]$, teaching and learning strategies $[15,16]$, and assessing knowledge or abilities [17,18] for understanding and detecting DV. However, little information is currently available on the clinical performance of medical students in encounters with patients experiencing DV.

In this study, we developed standardized patient (SP) stations of DV cases and evaluated the status of students' clinical performance to suggest several ideas to improve students' performance in DV. To be specific, first, students' clinical performance in DV station was compared with that in the other SP stations. Second, we analyzed the students' performance pattern in the DV station and determined the strong and weak points in their performance. Using these findings, we discuss the educational implications and suggest educational strategies to improve students' performance in DV assessment.

\section{Methods}

\section{Subjects}

This study was approved by the Dong-A University Institutional Review Board, Korea (IRB approval no., 2104709-AB-N-01-201710-HR-048-02). The subjects of this study were the scores of students obtained from DV stations in SP based examination held by BusanGyeongnam Clinical Skills Examination Consortium, which is an association of five medical schools in Busan-Gyeongnam region. The examinations were held from December 1st to 3rd in 2014 for the 3rd year students after their core clerkship and from July 18th to 21st in 2016 for the 4th year students after full process of their clerkship. The examination was composed of six stations relating to patient encounters and six stations relating to technical skills. The examinations were performed at three clinical simulation centers of different universities located in Busan. The station environments, training of SPs, and criteria of scoring were standardized. We analyzed 111 scores of 3rd year students and 143 scores of 4 th year students tested on the first day of the examinations, as we wanted to avoid the risk of score bias due to information sharing among students. Five universities of the consortium conduct the 
curriculum of a 2-year clinical clerkship after 2 years of preclinical integrated curriculum.

\section{DV case development}

The cases were developed by the case development committee of the consortium. The DV case for the 3rd year students was a child abuse case and the case for the 4th year students was an elder abuse case. In the child abuse case the student was to interview the victim's mother, but in elderly abuse case the student was to interview the victim. Instructions on the station door of each case are presented in Appendices 1 and 2.

A checklist was constructed to categorize the students' ability in history taking, patient education, and communication and interpersonal skills. The items on the checklist were developed based on basic texts from family medicine, emergency medicine, and psychiatry, objectives for evaluation [19,20], ethics objective structured clinical examination scenarios [21], and the guide to clinical performance [22]. The history taking and patient education during the encounter was scored as yes/no.

We selected four SPs who had been trained 20 hours of basic training and minimum of 5 years of experiences to the clinical skills examination. SP trainer of the consortium trained the SPs for total 4 hours for standardization of simulation and ratings. Via mock exam, case developers for this examination confirmed the standardization of the SP, station setting and the evaluation form. SP graded the students for the child abuse station and a professor graded the students after 1 hour of preceding education for the elderly abuse station.

\section{Data analysis}

The Cronbach's $\alpha$ value was calculated to determine the reliability of the examinations with IBM SPSS ver. 21.0 for Windows (IBM Corp., Armonk, USA).

We graded the students' scores on a scale of 100 points. The mean scores in relations to DV were compared with those of the other five SP stations tested in the same examination (Table 1).

In order to determine the performance pattern of students in the DV station, we categorized the items of the checklist according to the six domains for a successful DV interview (Tables 2, 3): (1) strategy for patients to disclose DV and building trust (D); (2) DV related history taking $(\mathrm{H})$; (3) checking the perpetrator's psycho-social state (P); (4) checking the victim's physical and psychological condition (V); (5) negotiation and persuasion about further plans with the victim or caregiver $(\mathrm{N})$; and (6) providing information about ethico-legal issues, diagnosis and treatment principles, and support services (I). The D domain contains discussion around confidentiality and questions to open for disclosure about DV. Questions in the H category are to determine who the perpetrator is and confirm who the victim is, and clarify the duration, pattern, and circumstances of the DV. The P domain focused on perpetrator's past and medical history of DV. Questions to check the victim's emotional

Table 1. Scores of 3rd and 4th Year-Medical Students Achieved from Six Stations with Patient Encountering on the Same Examination in Each Year

\begin{tabular}{|c|c|c|c|c|c|c|c|c|c|c|c|c|}
\hline & \multicolumn{6}{|c|}{ 3rd year students (2014) } & \multicolumn{6}{|c|}{ 4th year students (2016) } \\
\hline & $\begin{array}{c}\text { Acute } \\
\text { abdomen }\end{array}$ & Oliguria & Dyspnea & $\begin{array}{c}\text { Vaginal } \\
\text { discharge }\end{array}$ & $\begin{array}{l}\text { Child } \\
\text { abuse }\end{array}$ & Rhinorrhea & $\begin{array}{c}\text { Acute } \\
\text { abdomen }\end{array}$ & $\begin{array}{c}\text { Consciousness } \\
\text { disability } \\
\text { (hepatic coma) }\end{array}$ & Cough & $\begin{array}{c}\text { Elderly } \\
\text { abuse }\end{array}$ & $\begin{array}{l}\text { Mal-men } \\
\text { struation }\end{array}$ & $\begin{array}{l}\text { Back } \\
\text { pain }\end{array}$ \\
\hline Average & 66.1 & 64.2 & 64.0 & 57.3 & 50.6 & 48.1 & 63.8 & 61.5 & 60.3 & 57.1 & 52.7 & 49.1 \\
\hline $\begin{array}{l}\text { Standard } \\
\text { deviation }\end{array}$ & 10.0 & 14.1 & 11.9 & 10.2 & 13.3 & 15.0 & 11.3 & 10.6 & 8.2 & 12.4 & 9.5 & 8.3 \\
\hline
\end{tabular}


Table 2. Percentage of Students Who Have Practiced the Items and Interview Category of Each Item of Check List for Child Abuse

\begin{tabular}{|c|c|c|c|c|}
\hline No. & Items & Check point of items & $\begin{array}{l}\text { Interview } \\
\text { category }^{\text {al }}\end{array}$ & $\begin{array}{l}\% \text { of students } \\
\text { done }\end{array}$ \\
\hline 1 & I heard that secrecy was guaranteed. & Confidentiality & D & 42.3 \\
\hline 2 & $\begin{array}{l}\text { I heard that doctor wanted to help us because the child had } \\
\text { a lot of bruises. }\end{array}$ & Opening interviewee's mind & $D$ & 54.0 \\
\hline 3 & I told that patient's father bit patient. & Define perpetrator & H & 98.2 \\
\hline 4 & $\begin{array}{l}\text { I told that patient's father bit patient since he was } 6 \text { months } \\
\text { old. }\end{array}$ & Duration of DV & $\mathrm{H}$ & 49.5 \\
\hline 5 & I told that patient's father bit patient with a hand or a stick. & Pattern of DV & $\mathrm{H}$ & 36.0 \\
\hline 6 & I talked about the circumstances under which patient was bitten. & Circumstances of DV & H & 87.4 \\
\hline 7 & When patient's father bit patient, I could not do anything. & Care-giver's attitude during DV & H & 55.9 \\
\hline 8 & Patient's father bit only patient. & Confirm victim of DV & H & 63.1 \\
\hline 9 & $\begin{array}{l}\text { Patient's father has never received treatment for the cause of } \\
\text { violence. }\end{array}$ & Perpetrator's past history & $P$ & 4.5 \\
\hline 10 & $\begin{array}{l}\text { There is no sickness (including psychiatric illness) that patient's } \\
\text { father has been diagnosed otherwise. }\end{array}$ & Perpetrator's medical history & $P$ & 9.0 \\
\hline 11 & Nowadays patient has good emotional state and feelings. & Victim's emotional condition & V & 40.5 \\
\hline 12 & Patient eats well and sleeps well. & Victim's physical condition & V & 16.2 \\
\hline 13 & Patient does not have any developmental problem. & Victim's developmental state & V & 30.0 \\
\hline 14 & I heard this situation is to be child abuse. & Inform the situation as DV & I & 60.4 \\
\hline 15 & $\begin{array}{l}\text { In the case of child abuse, it was said that the medical person } \\
\text { was obliged to report. }\end{array}$ & $\begin{array}{l}\text { State legal duty of doctor to report } \\
\text { DV }\end{array}$ & N & 25.2 \\
\hline 16 & I heard that child abuse is subject to legal punishment. & State illegality of perpetrator & $\mathrm{N}$ & 16.2 \\
\hline 17 & I heard that patient and his father needed to be separated. & Further treatment to prevent DV & I & 51.4 \\
\hline 18 & $\begin{array}{l}\text { Patient, patient's father and I were invited to consult with mental } \\
\text { health department. }\end{array}$ & $\begin{array}{l}\text { Connect facility to treat DV related } \\
\text { persons }\end{array}$ & I & 90.0 \\
\hline
\end{tabular}

DV: Domestic violence.

${ }^{a}$ D: Disclosure strategy, H: DV related history taking, P: Checking perpetrator's psycho-social status, V: Checking victim's mental \& physical condition, $\mathrm{N}$ : Negotiation and persuade, I: Provide information for DV.

and physical conditions were in the V category. The $\mathrm{N}$ category contains questions to persuade the interviewee to take further treatment or isolation from the perpetrator, such as by providing warnings about the risk of DV, statements of the doctor's legal duty to report DV, and indicating the illegality of perpetrator's actions. The I category includes questions to inform the situation as DV, protection agencies and facilities to receive mental support. The frequency of each item and category was calculated with the percentage of students who completed it. Students' performance according to the domains is presented as the average score of items belonging to each category from both cases.

\section{Results}

The Cronbach's $\alpha$ value for the reliability of the DV station for 3rd year students in 2014 was 0.80 and the value of the examination for 4th year students taken in 2016 was 0.82 .

\section{Comparison of students' clinical perfor- mance in DV station to other stations}

As shown in Table 1, both groups of students showed poorer performance in the DV stations compared to other stations. Third year students scored an average of $50.6 \pm 13.3$ points in the child abuse station, which was the 2nd lowest among six stations. The highest score was 
$66.1 \pm 10.0$ obtained in the station with acute abdomen. Fourth year students obtained an average score of $57.1 \pm 12.4$ in the elderly abuse station, which was the third lowest among six stations. The highest score was $63.8 \pm 11.3$ relating to acute abdominal problems and the lowest was $49.1 \pm 8.3$ relating to back pain.

\section{Students' performance pattern}

Table 2 presents the checklist items and the percentage of students who performed each item in the child abuse station. The items most students completed are: 'define the perpetrator' (98.2\%), 'circumstances of the victim bitten' (87.4\%), and 'recommend consultation with the mental health department" (90.0\%). However, students did not pay attention to the perpetrator's psycho- pathologic status (category P, $4.5 \%$ and $9.5 \%$ ), or the victim's physical and psychological status (category V, $16.2 \%$ and $30.0 \%$. In addition, the students did not declare either the legal duty of the doctor to report the DV or the legal punishment for the perpetrator (category N, $25.2 \%$ and $16.2 \%)$.

The percentage of students who completed the items on the checklist in the elder abuse scenario is presented in Table 3. The item most students performed is the confidentiality guarantee (81.8\%). The students paid little attention to the perpetrator's psychopathologic status (category P: item 7, 17.5\%) or the victim's physical and psychological status (category V: item 11, 30.8\%). Students did not discuss legal issues (category N: item 14, 16.1\%) or consequences when DV is ignored (category $\mathrm{N}$ :

\begin{tabular}{|c|c|c|c|c|}
\hline No. & Items & Check point of items & $\begin{array}{l}\text { Interview } \\
\text { category }^{\text {a) }}\end{array}$ & $\begin{array}{l}\% \text { of students } \\
\text { done }\end{array}$ \\
\hline 1 & I told that I came alone. & Check presence of care-giver & V & 8.4 \\
\hline 2 & I heard that the contents of counseling would not disclose to others. & Confidentiality & D & 81.8 \\
\hline 3 & I told that my son beat me for 2 years. & Duration of DV & $\mathrm{H}$ & 60.1 \\
\hline 4 & I told that my son drank and beat me about once a week. & Frequency of DV & $\mathrm{H}$ & 58.7 \\
\hline 5 & I told that my son was hating and shouting. & Associated actions with DV & $\mathrm{H}$ & 55.9 \\
\hline 6 & I told that my son sometimes smashed or threw things. & Other violence of perpetrator & $\mathrm{H}$ & 62.2 \\
\hline 7 & $\begin{array}{l}\text { He has never received treatment in the cause of violence or verbal } \\
\text { abuse. }\end{array}$ & Perpetrator's treatment history & $P$ & 17.5 \\
\hline 8 & There is no one to help me. & Victim's situation during DV & $\mathrm{H}$ & 55.9 \\
\hline 9 & When he was sober after violence, my son is nice. & Perpetrator's action after DV & $\mathrm{H}$ & 59.4 \\
\hline 10 & I told that I was not feeling well. & Victim's emotional condition & V & 50.3 \\
\hline 11 & I told that I had never thought about suicide. & Victim's suicidal urge & V & 30.8 \\
\hline 12 & I heard that this situation is to be elderly abuse. & Inform the situation as DV & I & 51.0 \\
\hline 13 & I heard that I can be at risk if the violence got worse. & Warn risk of DV if not treated & $\mathrm{N}$ & 28.7 \\
\hline 14 & $\begin{array}{l}\text { I heard that it is the duty of the medical person to report this } \\
\text { case as elderly abuse. }\end{array}$ & $\begin{array}{l}\text { State legal duty of doctor to report } \\
\text { DV }\end{array}$ & $\mathrm{N}$ & 16.1 \\
\hline 15 & $\begin{array}{l}\text { I heard that doctor understood my notion that I wanted to bury } \\
\text { this situation. }\end{array}$ & Encourage to open about DV & $\mathrm{N}$ & 34.3 \\
\hline 16 & $\begin{array}{l}\text { I heard that I could get help from nearby people or the police } \\
\text { in a violent situation. }\end{array}$ & Inform that police can help victim & I & 59.4 \\
\hline 17 & $\begin{array}{l}\text { I heard that the relevant agency can help me and I can stay in } \\
\text { the protection agency. }\end{array}$ & Inform protection agency to stay & I & 68.5 \\
\hline 18 & I was recommended to consult with the mental health department. & Inform facility to get mental support & 1 & 50.3 \\
\hline
\end{tabular}

DV: Domestic violence.

${ }^{a}$ D: Disclosure strategy, H: DV related history taking, P: Checking perpetrator's psycho-social status, V: Checking victim's mental \& physical condition, $\mathrm{N}$ : Negotiation and persuade, l; Provide information for DV. 
Table 4. Clinical Performance of Students on DV according to the Interview Categories

\begin{tabular}{|c|c|c|c|}
\hline \multirow{2}{*}{ Interview category } & \multicolumn{2}{|c|}{ No. of item } & \multirow{2}{*}{ Average $\%$ of students done } \\
\hline & Child abuse & Elderly abuse & \\
\hline D: Disclosure strategy & 1,2 & 2 & 59.4 \\
\hline H: DV related history taking & $3,4,5,6,7,8$ & $3,4,5,6,9$ & 62.4 \\
\hline P: Checking perpetrator's psycho-social status & 9,10 & 7 & 10.3 \\
\hline V: Checking victim's mental \& physical condition & $11,12,13$ & $1,10,11$ & 29.4 \\
\hline N: Negotiation and persuasion & 15,16 & $13,14,15$ & 24.1 \\
\hline I: Provide information on DV & $14,17,18$ & $8,12,16,17,18$ & 60.9 \\
\hline
\end{tabular}

DV: Domestic violence.

item 13, 28.7\%), and they showed less empathy (category $\mathrm{N}$ : item 13,14 , and $15,28.7 \%$ and $34.3 \%$ ).

The performance pattern was analyzed by categorizing the interview items shown in Table 4. There was no difference between 3 rd \& 4th year students in the performance pattern. Students performed moderately in three categories, namely "DV related history taking" (63.1\%), "providing information about DV ethico-legal issues and services" (60.3\%), and "strategies for patients to disclose DV and building trust" (59.4\%). However, fewer students performed the items in the three categories of "checking the patient's physical and psychological condition" (33.6\%), "negotiation and persuasion about further plan with patients" (24.1\%), and "checking the perpetrator's psycho-social state" (10.3\%).

\section{Discussion}

Students' performance in DV cases was investigated for the first time in Korea in the present study. The results of this study showed that students' performance in the DV station was poor compared to other stations. The students were good at DV related history taking, strategies to help patients disclose DV, and providing information about DV. However, most students ignored determining the physical and psychological condition of the victims and perpetrators. They also did not focus on negotiation and persuasion. Their interviews with the victims of DV were not structured and their explanations and planning were not skillful in terms of communication and interpersonal skills.

In this study, students' clinical performance was poor in the DV station compared to the others, especially in considering psychosocial status and negotiation. In addition, students received lower scores in communication and interpersonal skills than those from the other stations. The students' interviews were not organized enough. There may be several causes for the students' poor performance. First, students might not have been educated enough through their curriculum to deal with DV victims. Second, students might have much less experience in DV cases than other cases during their clerkship. Third, students might have no opportunities to acquire a high level of communication skills to interview suspected victims even though DV education was conducted. The authors think that students were less prepared for DV and became embarrassed during the interview with DV victims. If preparation and supervision is not adequate, physicians may suffer the stress of caring for abused patients, and later experience countertransference, compassion fatigue, or burnout [23]. They need more experience in encountering DV patients in clinics or even simulated environments during their curriculum. In addition, medical educators should pay more attention to DV education being integrated with 
communication skills. However, there could be another causes according to the school context, it would be helpful to investigate the education program for DV for further research.

The general pattern of students' performance in DV stations was not 'patient centered' but 'event centered' in this study. The students defined the perpetrator, focused on the violence itself, and finally suggested a solution, such as psychological counseling. This kind of pattern was also defined among primary healthcare clinicians in England [1,24]. Most general practitioners considered their roles in DV mainly as identifying DV and providing help by referral to external agencies. Some thought that they did not have to address all other aspects, as it was not their role. It is very important to perform patient centered interviews to establish all indications of DV and make a decision with partnership to provide support and safety to the patient. Therefore, medical educators should focus on learners' perspectives about DV during education and emphasize the importance of patient centered interview.

In this study, many students did not discuss legal issues. However, special case law regarding the punishment of home violence crime and laws regarding home violence prevention and victim protection had already been established in 1997 in Korea. DV is defined as a criminal act [25] and all medical personnel who detect DV have the responsibility to report it [26]. It is not clear whether the students understand this responsibility enough as they may not say anything in the exam contexts. However, educating students about DVrelated legal issues is recommended, as legal responsibility is important to detect and prevent DV. Therefore, medical educators should also focus on ethico-legal issues about DV during education.

In real clinical contexts, physician should be suspicious about DV when they meet any patient with physical problems. However, detection rates by physicians and medicals students are reported to be poor [23]. Fisher et al. [16] applied simulation to teach identification of elderly abuse to medical students. They reported several barriers to diagnosing DV by students, such as low index of suspicions, overly optimistic regard, and confused nomenclature. They concluded that clinical teachers who deliver DV education should focus on increasing students' index of suspicion. Therefore, education and examination on DV should initially focus on developing the ability to recognize DV [23].

DV recognition and treatment is an integral component [27] of medicine and should be taught in an integrated way, including patient safety, professionalism, ethics, laws, and communication skills. Intervention during clerkship was reported to be effective in previous studies. Didactic instruction to preclinical medical students improved the knowledge and attitudes on DV during clinical rotation [28]. Haist et al. [29] reported that a four-hour workshop dealing with four different cases of DV during 3rd year clerkship improved the knowledge and skills of medical students about DV.

In conclusion, 3rd and 4th year medical students showed event oriented clinical performance but not a patient centered interview with victims or caregivers in the station of DV. It is necessary to develop integrated educational programs dealing with various cases of DV to improve students' performance in the contexts of DV.

\section{ORCID:}

Hyun-Hee Kong: https://orcid.org/0000-0003-1075-0051;

Sunju Im: https://orcid.org/0000-0002-3038-3570;

Ji-Hyun Seo: https://orcid.org/0000-0002-0691-3957;

Do-Kyong Kim: https://orcid.org/0000-0001-8639-1951;

HyeRin Roh: https://orcid.org/0000-0002-3879-709X

Acknowledgements: None. 
Funding: None.

Conflicts of interest: No potential conflict of interest relevant to this article was reported.

Author contributions: Conception or design of the work: HHK, SJI, JHS, DKK, HRR; data collection: HHK, SJI; data analysis and interpretation: HHK, JHS; drafting the article: HHK; critical revision of the article: HRR; and final approval of the version to be published: HHK, SHI, JHS, DKK, HRR.

\section{References}

1. Ramsay J, Rutterford C, Gregory A, et al. Domestic violence: knowledge, attitudes, and clinical practice of selected UK primary healthcare clinicians. Br J Gen Pract. 2012;62(602):e647-e655.

2. Council of Europe. Council of Europe convention on preventing and combating violence against women and domestic violence. https://rm.coe.int/168008482e. Accessed November 1, 2017.

3. World Health Organization. Understanding and addressing violence against women: overview. http://apps.who.int/ iris/bitstream/10665/77433/1/WHO_RHR_12.35_eng.pd f?ua $=1$. Accessed November 1, 2017.

4. Garcia-Moreno C, Jansen HA, Ellsberg M, Heise L, Watts CH; WHO Multi-country Study on Women's Health and Domestic Violence against Women Study Team. Prevalence of intimate partner violence: findings from the WHO multi-country study on women's health and domestic violence. Lancet. 2006;368(9543):1260-1269.

5. Yon Y, Mikton CR, Gassoumis ZD, Wilber KH. Elder abuse prevalence in community settings: a systematic review and meta-analysis. Lancet Glob Health. 2017; 5(2):el47-el56.

6. World Health Organization. Global status report on violence prevention 2014. http://apps.who.int/iris/bitstream/10665/ 145086/1/9789241564793_eng.pdf?ua= l \&ua=1.

Accessed November 1, 2017.

7. Shefet D, Dascal-Weichhendler H, Rubin O, et al. Domestic violence: a national simulation-based educational program to improve physicians' knowledge, skills and detection rates. Med Teach. 2007;29(5):el33-el38.

8. Alpert EJ, Tonkin AE, Seeherman AM, Holtz HA. Family violence curricula in U.S. medical schools. Am J Prev Med. 1998;14(4):273-282.

9. Davies VA. Domestic violence: we need changes in the ICD and at the start of training. Br J Psychiatry. 201 l; 198(6):492.

10. Korean Association of Medical Colleges. Learning outcomes of basic medical education: clinical competencycentered. 2nd ed. Paju, Korea: GabU Munhwasa; 2016.

11. Lee YS. OSCE for the Medical Licensing Examination in Korea. Kaohsiung J Med Sci. 2008;24(12):646-650.

12. Fogarty CT, Burge S, McCord EC. Communicating with patients about intimate partner violence: screening and interviewing approaches. Fam Med. 2002;34(5):369-375.

13. Chen PH, Gerstmann M, Padilla D, Barrett T. Training future physicians to screen for and intervene with domestic violence. Med Educ. 2016;50(5):585.

14. Short LM, Cotton D, Hodgson CS. Evaluation of the module on domestic violence at the UCLA School of Medicine. Acad Med. 1997;72(1 Suppl):S75-S92.

15. Ross S, Heys S, Galley H. Using live theatre in teaching about domestic abuse. Med Educ. 2010;44(5):503-504.

16. Fisher JM, Rudd MP, Walker RW, Stewart J. Training tomorrow's doctors to safeguard the patients of today: using medical student simulation training to explore barriers to recognition of elder abuse. J Am Geriatr Soc. 2016;64(1):168-173.

17. Ernst AA, Houry D, Weiss SJ, Szerlip H. Domestic violence awareness in a medical school class: 2-year follow-up. South Med J. 2000;93(8):772-776.

18. Hoffstetter SE, Blaskiewicz RJ, Furman GE, McCabe JA. 
Medical student identification of domestic violence as measured on an objective, standardized clinical examination. Am J Obstet Gynecol. 2005;193(5):1852-1855.

19. Korea Health Personnel Licensing Examination Institute. Evaluation objectives for Korean Medical Licensing Exam (clinical skills exam). http://www.kuksiwon.or.kr/Publicity/ InfoOpenView.aspx?SiteGnb $=2 \&$ SiteLnb $=4 \&$ SiteLnbO neDepth $=1 \& D A T A \_S E Q=116$. Accessed November 1 , 2017.

20. The Medical Council of Canada. Objectives for the qualifying examination. http://mcc.ca/wp-content/uploads/Qualifyingexamination-objectives.pdf. Accessed November 1, 2017.

21. Singer PA, Robb AK. The ethics OSCE: standardized patient scenarios for teaching and evaluating bioethics. http://hdl.handle.net/10822/869473. Accessed November $1,2017$.

22. Sunwoo S. Domestic violence. In: Korean Association of Medical Colleges, ed. The Guide to Clinical Performance. Paju, Korea: GabU Munhwasa; 2016:747-755.

23. Thompson-McCormick J, Jones L, Cooper C, Livingston G. Medical students' recognition of elder abuse. Int J Geriatr Psychiatry. 2009;24(7):770-777.
24. Yeung H, Chowdhury N, Malpass A, Feder GS. Responding to domestic violence in general practice: a qualitative study on perceptions and experiences. Int J Family Med. 2012;2012:960523.

25. Park YS. A study in terms of the actuality and countermeasure of home violence. Korean Police Stud Rev. 2016;15(2):89-112.

26. Ahn KO, Eo EK, Cheon YJ, Jung KY. Practical analysis of medical care of domestic violence victims in emergency department. J Korean Soc Emerg Med. 2002; 13(1):84-89.

27. Dickstein LJ. Practical recommendations for supporting medical students and faculty in learning about family violence. Acad Med. 1997;72(1 Suppl):S105-S109.

28. Haase CE, Short PD, Chapman DM, Dersch SA. Domestic violence education in medical school: does it make a difference? Acad Emerg Med. 1999;6(8):855857.

29. Haist SA, Wilson JF, Pursley HG, et al. Domestic violence: increasing knowledge and improving skills with a four-hour workshop using standardized patients. Acad Med. 2003;78(10 Suppl):S24-S26. 
Hyun-Hee Kong, et al: Clinical performance in domestic violence

\section{Appendix 1. Candidate Instruction on the Station Door for 'Child Abuse'}

Three-year-old boy, Kim Sung-Hoon, was injured and received treatment after visiting the emergency room with his family. A fracture of his right arm required a plaster bandage, and physical examination revealed bruises and contusions on his upper body and arms from different times (refer to medical record).

\begin{tabular}{ll}
\hline$<$ Vital signs $>$ & \\
\hline Blood pressure: $100 / 60 \mathrm{mmHg}$ & Pulse: $96 / \mathrm{min}$ \\
Respiration rate: $24 / \mathrm{min}$ & Body temperature: $36.6^{\circ} \mathrm{C}$ \\
Height: $95 \mathrm{~cm}$ & Body weight: $12 \mathrm{~kg}$ \\
\hline
\end{tabular}

Candidates, considering child abuse

- Take history regarding domestic violence from patient's mother.

- Discuss his diagnosis and future treatment plans with his mother.

\section{Appendix 2. Candidate Instruction on the Station Door for 'Elder Abuse'}

A 65-year-old woman, Kim Young-Soon, came to the hospital because her right breast was sore. She was diagnosed with a rib fracture. Multiple bruises were found on both her wrists and arms.

\begin{tabular}{ll}
\hline$<$ Vital sign $>$ & \\
\hline Blood pressure: $120 / 80 \mathrm{mmHg}$ & Pulse: $70 / \mathrm{min}$ \\
Respiration rate: $18 / \mathrm{min}$ & Body temperature: $36.6^{\circ} \mathrm{C}$ \\
Height: $160 \mathrm{~cm}$ & Body weight: $50 \mathrm{~kg}$ \\
\hline
\end{tabular}

Candidates, considering domestic violence

- Take history regarding domestic violence.

- Perform physical examination in relation to domestic violence.

- Discuss the diagnosis and future treatment plans with the patient. 